\title{
Early Treatment of Diabetic Retinopathy Study Eye Chart
}

National Cancer Institute

\section{Source}

National Cancer Institute. Early Treatment of Diabetic Retinopathy Study Eye Chart. NCI

Thesaurus. Code C117877.

A diagrammatic method to test visual acuity which incorporates the Bailey-Lovie layout in conjunction with Sloan optotypes, which was first used in the Early Treatment of Diabetic Retinopathy Study. 